\title{
Anti-reflux procedure for difficult-to-treat asthmatic children, case report and literature review
}

\author{
Zhi-Wei Hu', Zhong-Gao Wang ${ }^{1,2,4^{*}}$, Ji-Min Wu' and Song-Tao Tan ${ }^{3}$
}

\begin{abstract}
Gastroesophageal reflux disease (GERD) is a commonly encountered condition in children, which at times causes respiratory distress, such as asthmatic symptoms, and results in serious morbidity and even mortality. The complexity is sometimes so obscure, that it can cause paradoxical diagnoses and treatment. Here we present two cases of children with difficult-to-treat asthmatic symptoms, which were eventually found to be related to GERD. The two children were treated with anti-reflux procedures and both became symptom free. Literature was also reviewed to shed a light into this complex disease.
\end{abstract}

Keywords: Gastroesophageal reflux disease, Difficult-to-treat Asthma, Children, Stretta frequency, Laparoscopic fundoplication

\section{Case I}

It was a 12 year-old girl, who had frequent cough and wheezing which required hospital visits and intravenous anti-asthmatic medication every year, since she was two years old. However, after she was ten her symptoms worsened when her wheezing became daily episodes accompanied with violent cough which could last for one or two hours before remission, making her difficult to lie down at midnight. She also reported sneezing, eyeitching and tearing before the onset of cough and wheezing, but no notable heartburn or regurgitation was recalled. During the years, despite her longing to improve grades in school, she often had to cut school due to hospital visits or fatigue, Her family had consulted five major hospitals in different provinces, in addition to almost all the local hospitals. The diagnosis was always the same: allergic asthma. Her spirometry test showed $16 \%$ improvement in $\mathrm{FEV}_{1}$ after inhaling albuterol and the only one positive skin prick test result was housedust mites four years ago. Despite maximum dose of oral corticosteroid and Beta-agonists inhaling, or traditional

\footnotetext{
* Correspondence: zhonggaowang@126.com

'Xuanwu Hospital of Capital Medical University, Beijing, China

${ }^{2}$ Center for GERD, Second Artillery General Hospital of Beijing Normal

University, Beijing, China

Full list of author information is available at the end of the article
}

Chinese medicine, her symptoms seemed to be uncontrollable. At last, she came to us for gastroesophageal reflux (GER) evaluation to find out if the asthmatic symptom is second to GER. The routine 24-hour $\mathrm{pH}$ monitoring showed pathological acid reflux (DeMeester score: 25.45), which was more severe in supine position. And the longest reflux (18.1 min) occurred at one midnight when she had an asthma attack. According to the data we concluded that her asthma was GER related. We conducted Stretta Frequency (SRF) procedure on the patient after having approval from the hospital's ethics research committee and obtaining parental consent from the patient's family. Since the day of the anti-reflux treatment, the patient can sleep well and until now her handicapping symptoms have disappeared for 31 months without medication.

\section{Case 2}

In this case the patient is a boy. Since he was born in 1997, his mother found he was difficult to feed due to frequent belching and regurgitation of milk into his mouth and nasal cavity. At the age of six, wheezing, short of breath and productive chough caused him to be hospitalized and the disease was treated as "pneumonia". Since then until he aged ten, his repeated "pneumonia" forced him to be taken into hospital almost every month, 
with each hospital stay lasting about ten days. Through the years he usually had productive cough for one or two days before onset of wheezing and short of breath. He was also diagnosed as affected with "allergic asthma" in other hospitals though allergen was not identified. All kinds of anti-asthmatic medications (oral, intravenous or inhaled) had been tried, which were all helpless in preventing the disease from getting worse. Despite constant and marked symptoms of belching and regurgitation, accompanied by astigmatism and sore throat started since age ten, these symptoms were neglected and untreated by his family and physicians. Through the Internet, the desperate mother found us and brought the boy for GER evaluation.

On admission, the patient was a lean adolescent appearing to be healthy with no signs of respiratory distress. His chest film showed mild emphysema, total IgE plasma level was normal $(12.90 \mathrm{IU} / \mathrm{ml})$ and the esophagogastroduodenoscopy showed a sliding hiatal hernia and non-erosive reflux disease (NERD) (Figure 1). A following esophagus manometry also found the hernia and

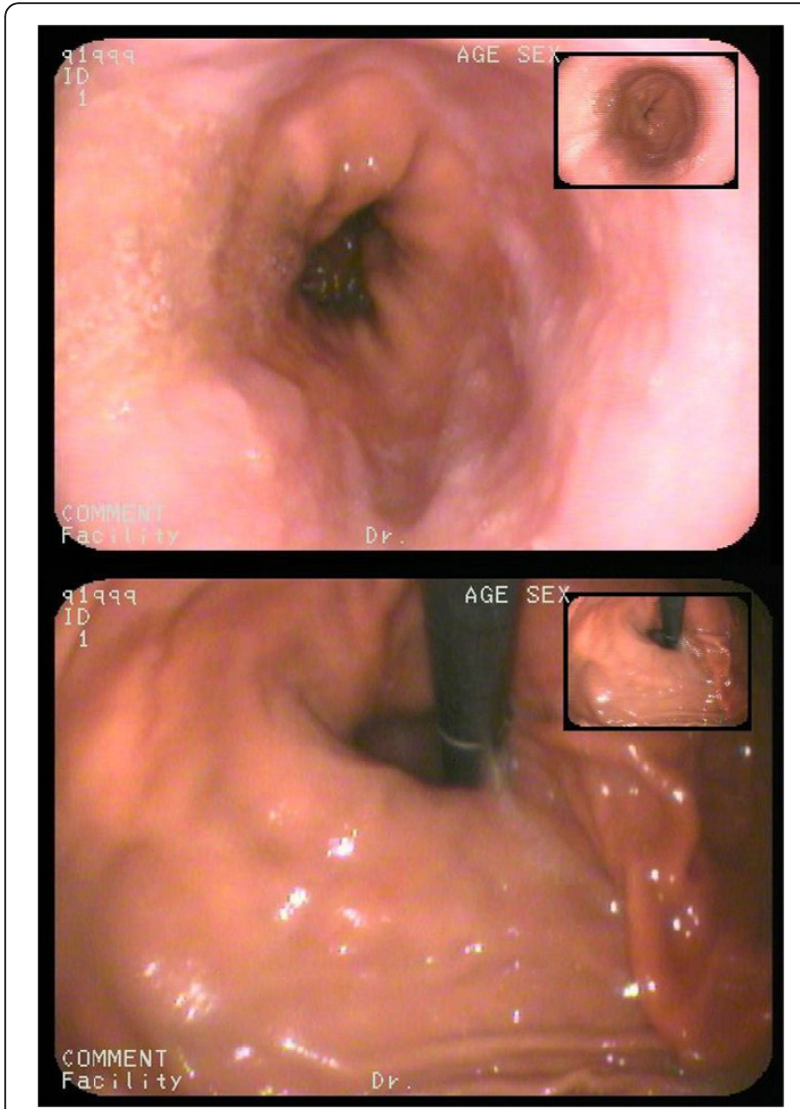

Figure 1 In case 2, a hiatus hernia without esophagitis was identified under endoscopy, which was considered as the cause of the boy's persistent and evident GER and then the difficultto-treat asthmatic symptom. And this anatomical defect indicates a surgical intervention. showed a hypotensive short lower esophageal sphincter (LES) and abnormal esophageal contraction waves. We concluded that his hiatal hernia, GER and asthmatic symptoms were related. Laparoscopic Nissen fundoplication (LNF) and hiatal hernia repair were performed on him. After the surgery, we have followed up the boy for 15 months and found that episodic respiratory distress, "pneumonia", and his belching and regurgitation were cleared up.

\section{Discussion}

Gastroesophageal reflux disease (GERD) is a commonly encountered condition in childhood [1]. Refluxassociated extraesophageal symptoms in infants and children include serious events, such as oxygen desaturation, episodes of apnea, recurrent aspiration, as well as symptoms such as asthma, bronchitis, irritability, and sleep disturbances, which apparently may result in serious morbidity, even mortality [2,3]. In the first three months of life, postprandial reflux is considered a physiological event which gradually decreases and disappears by one year of age [4]. The progressive decrease in episodes is due to maturation of the LES and to acquisition of sitting and standing. However, some children have persistent regurgitation or reflux after the first year of age. Their reflux is not only associated with feeding but also with backwardness, behavioral disorders such as irritability, unjustified crying and sudden waking, and persistent esophageal hiatus defect [5].

Similar to GERD, asthma is also a common disease with chronic complex inflammatory airway disorder, which is characterized by variable degrees of recurring symptoms of airflow obstruction and bronchial hyper responsiveness [6]. Although the majority of asthma patients may obtain the targeted level of control, some patients will not achieve control even with the best therapy [7]. Patients who do not reach an acceptable level of control with reliever medication plus two or more controllers can be considered to have difficult-to-treat asthma [8]. The lives of children with difficult-to-treat asthma are severely disrupted with frequent hospital visits, school absence, and limitation of normal activities. Behavioural problems and a lower quality of life are more pronounced in those children [9]. Persistent airflow limitation is present in a proportion of these patients [10]. Although they probably account for less than $5 \%$ of all children with asthma, the management of this group of children is difficult, with little evidence to guide the choice of further treatment for those who remain symptomatic even after the use of regular systemic corticosteroids.

The association between asthma and GER has been debated for decades after Sir William Osler first observed the association between worsening asthma and distended 
stomach in 1892 [11]. The prevalence of GERD in children with asthma ranged from $19.3 \%$ to $80.0 \%$ and averaged $22.8 \%$. In patients with asthma, the average prevalence of abnormal esophageal $\mathrm{pH}$ was $68.2 \%$ and of esophagitis was $35.6 \%$. GERD was found in about $49 \%$ of patients with childhood difficult-to-treat asthma [12] and a hiatal hernia often predicts a higher risk of GERD due to the anatomical defect [13].

The diagnosis of GER is not easy in some children with asthmatic symptom. GER may be present with bronchiolitis, pneumonitis, and even failure to thrive. Other common GER respiratory manifestations are chronic coughing, asthma, laryngeal spasm, apnea, stridor, pulmonary dysplasia, and cyanotic crises. Nocturnal wheezing or coughing with inadequate response to medical treatment for asthma, negative family history of atopy, and early onset of bronchial hyperreactivity can distinguish these patients [14]. GER typically has symptoms such as heartburn and/or regurgitation. However the prevalence of asymptomatic acid reflux in patients with asthma varies between $10 \%$ and $62 \%$ according to the underlying severity of the asthma and the measure used to identify symptoms [15]. Thus, there is a need for tests to predict the presence of GER among children with difficult-to-treat asthma. 24-h intra-esophageal $\mathrm{pH}$ monitoring is one of the current reference-standard methods for GER assessment in children [16]. Multichannel intraluminal impedance and $\mathrm{pH}$ (MII-pH) monitoring can detect anterograde or retrograde acid or non-acid bolus and determine the composition (liquid, gas and mixed) movement into the esophagus, as well as the height reached by the refluxate [17]. Endoscopy is sensitive for esophagitis and hiatal hernia. Esophagus manometry is valuable for demonstration of esophageal dyskinesia, hypotonia of the LES or the presence of hiatal hernia. An easy-to-conduct barium swallow study is useful to detect hiatus hernia or spontaneous reflux. These modalities may have important diagnostic and therapeutic implications for children with reflux-related respiratory problems. Recently, a study by Dal Negro et al. showed that esophageal acidification has a good level of both sensitivity and specificity by enhancing the $\mathrm{MCh}$ response in FEV1 only in the presence of acid GER. This test could be a potentially useful tool for better selection of GER-related asthma from the asthmatics in clinical practice [18].

Reflux management strategies focus on two main areas: First, to use effective agents to reduce acid secretion and thus the likely damage to the esophagus and lungs from their long-term or repeated exposure to acidic gastric contents. Proton pump inhibitor (PPI) therapy is currently the most accepted medical therapy in children, as it is in adults. However, PPI failed to show benefit in terms of asthma control in children with
GERD in most of the well-designed studies [19]. Despite the current lack of population based studies and longitudinal studies, PPI still could be a valuable empiric treatment for well selected asthmatic children with GERD. Second, to correct some of the anatomic abnormalities. By artificial means, it is to increase tonicity and to restore functions of the lower esophageal sphincter to some degree. For a patient who has difficult-to-treat asthma, whether the etiology is primary or secondary to an underling disorder such as GERD must be clarified. To treat cases of GER related asthmatic symptoms, fundoplication or some other procedures should be considered for patients who have failed maximal medical therapy, who are not proper candidates to undergo medical therapy for some special reasons, and who have hiatal hernia contributing to the reflux. It is essential to confirm that any existing anatomic or neurophysiologic defects are either remedied first or are considered as one part of the GERD management as well. Since 2006 when we established a Center for GERD to diagnose and to treat GERD patients with asthmatic symptoms using SRF or LNF, some good results have been documented for adult patients [20]. Effectiveness of surgical therapy in different uncontrolled series in children with severe persistent asthmas have also been reported [21-23], which shed a light on potential alternative or promising therapy for difficult-to-treat or uncontrolled asthmatic for children.

\section{Consent}

Written informed consents were obtained from the patients for publication of this case report and for any associated images. A copy of the written consents is available for review by the Editor-in-Chief of this journal.

\section{Abbreviations \\ GERD: Gastroesophageal Reflux Disease; SRF: Stretta frequency; LES: Lower esophageal sphincter.}

\section{Competing interests}

The authors declare that they have no competing interests.

\section{Authors' contributions}

ZW Hu studied and analyzed the two cases, conducted literature reviews, and drafted the manuscript. ZG Wang designed the study and helped to draft the manuscript. JM Wu and ST Tan carried out the study, collected the data and helped to draft the manuscript. All authors read and approved the final manuscript.

\section{Authors' information}

ZW Hu, the resident in training program in Center for GERD of Second Artillery General Hospital; ZG Wang, the professor and director of Center for GERD of Second Artillery General Hospital, Professor and Director of vascular institution of Xuanwu Hospital of Capital Medical University Capital, Life Long President of China Vascular Society, Vice President of International Society of Vascular Surgery and Academician of China Academy of Science. JM Wu, director of Center for GERD of Second Artillery General Hospital, ST Tan, director of Center for GERD, Wu Jing Zong Dui Hospital of Guangdong Province. 


\section{Acknowledgments}

We thank Vivian Zhao PhD. for the linguistic revision.

\section{Author details}

${ }^{1}$ Xuanwu Hospital of Capital Medical University, Beijing, China. ${ }^{2}$ Center for GERD, Second Artillery General Hospital of Beijing Normal University, Beijing, China. ${ }^{3}$ Center for GERD, Wu Jing Zong Dui Hospital of Guangdong Province, Guangzhou, China. ${ }^{4}$ No. 16 Xinwai Street, Xicheng district, Beijing 100088, China.

Received: 3 July 2012 Accepted: 7 September 2012

Published: 14 September 2012

\section{References}

1. Hassall E: Decisions in diagnosing and managing chronic gastroesophageal reflux disease in children. J Pediatr 2005, 146:S3-S12.

2. Thach BT: Reflux associated apnea in infants: evidence for a laryngeal chemoreflex. Am J Med 1997, 103:120S-124S.

3. Orenstein SR: An overview of reflux-associated disorders in infants: apnea, laryngospasm, and aspiration. Am J Med 2001, 111(Suppl 8A):60S-63S.

4. Orenstein SR: Infantile reflux: different from adult reflux. Am J Med 1997, 103:114S-119S.

5. Bouchard S, Lallier M, Yazbeck S, Bensoussan A: The otolaryngologic manifestations of gastroesophageal reflux: when is a $\mathrm{pH}$ study indicated? J Pediatr Surg 1999, 34:1053-1056.

6. Expert Panel Report 3 (EPR-3): Guidelines for the Diagnosis and Management of Asthma-Summary Report 2007. J Allergy Clin Immunol 2007, 120:S94-S138

7. Nathan RA, Sorkness CA, Kosinski M, Schatz M, Li JT, Marcus P, Murray JJ, Pendergraft TB: Development of the asthma control test: a survey for assessing asthma control. J Allergy Clin Immunol 2004, 113:59-65.

8. Wenzel SE: Severe asthma in adults. Exp Lung Res 2005, 31:1-22. Suppl.

9. Verkleij M, van de Griendt EJ, Kaptein AA, van Essen-Zandvliet L, Duiverman E, Geenen R: Behavioral Problems in Children and Adolescents with Difficult-To-Treat Asthma. Journal of Asthma 2011, 48:18-24.

10. Chan MT, Leung DY, Szefler SJ, Spahn JD: Difficult-to-control asthma: clinical characteristics of steroid-insensitive asthma. J Allergy Clin Immunol 1998, 101:594-601.

11. Kalach N, Gumpert L, Contencin P, Dupont C: Dual-probe pH monitoring for the assessment of gastroesophageal reflux in the course of chronic hoarseness in children. Turk J Pediatr 2000, 42:186-191.

12. Thakkar K, Boatright RO, Gilger MA, El-Serag HB: Gastroesophageal Reflux and Asthma in Children: A Systematic Review. Pediatrics 2010, 125:E925-E930.

13. Hyun JJ, Bak YT: Clinical significance of hiatal hernia. Gut Liver 2011, 5:267-277.

14. Ay M, Sivasli E, Bayraktaroglu Z, Ceylan H, Coskun Y: Association of asthma with gastroesophageal reflux disease in children. J Chin Med Assoc 2004, 67:63-66.

15. Asano K, Suzuki H: Silent acid reflux and asthma control. N Engl J Med 2009, 360:1551-1553.

16. Rudolph CD, Mazur LJ, Liptak GS, Baker RD, Boyle JT, Colletti RB, Gerson WT, Werlin SL: Guidelines for evaluation and treatment of gastroesophageal reflux in infants and children: recommendations of the North American Society for Pediatric Gastroenterology and Nutrition. J Pediatr Gastroenterol Nutr 2001, 32(Suppl 2):S1-S31.

17. Borrelli O, Battaglia M, Galos F, Aloi M, De Angelis D, Moretti C, Mancini V, Cucchiara S, Midulla F: Non-acid gastro-oesophageal reflux in children with suspected pulmonary aspiration. Digestive and Liver Disease 2010, 42:115-121.

18. Dal Negro RW, Tognella S, Micheletto C, Sandri M, Guerriero M: A MCh test pre-post esophageal acidification in detecting GER-related asthma. J Asthma 2009, 46:351-355.

19. Martinez FD: Children, asthma, and proton pump inhibitors: costs and perils of therapeutic creep. JAMA 2012, 307:406-407.

20. Wang Z, Kotwal RM: Is GERD-induced asthma a different disease entity? Ther Adv Respir Dis 2012, 6:57.

21. Khoshoo V, Le T, Haydel RM Jr, Landry L, Nelson C: Role of gastroesophageal reflux in older children with persistent asthma. Chest 2003, 123:1008-1013.
22. Farcau D, Dreghiciu D, Chereches-Panta P, Popa M, Farcau M, Nanulescu M: [Effectiveness of antireflux therapy in asthmatic children with gastroesophageal reflux disease]. Pneumologia 2004, 53:207-211.

23. Khoshoo V, Mohnot S, Haydel R Jr, Saturno E, Edell D, Kobernick A Bronchial hyperreactivity in non-atopic children with asthma and reflux: effect of anti-reflux treatment. Pediatr Pulmonol 2009, 44:1070-1074.

doi:10.1186/2049-6958-7-28

Cite this article as: Hu et al:: Anti-reflux procedure for difficult-to-treat asthmatic children, case report and literature review. Multidisciplinary Respiratory Medicine 2012 7:28.

\section{Submit your next manuscript to BioMed Central and take full advantage of:}

- Convenient online submission

- Thorough peer review

- No space constraints or color figure charges

- Immediate publication on acceptance

- Inclusion in PubMed, CAS, Scopus and Google Scholar

- Research which is freely available for redistribution

Submit your manuscript at www.biomedcentral.com/submit
C) Biomed Central 